Konrad Dziobek ${ }^{1}$, Zbigniew Kojs², Sebastian Szubert ${ }^{3}$, Sławomir Wileński ${ }^{3}$, Maria Szymankiewicz ${ }^{4}$, Łukasz Wicherek $^{3}$, Magdalena Dutsch-Wicherek ${ }^{5}$

${ }^{1}$ Centrum Onkologii w Bydgoszczy, Center of Oncology, M. Sklodowska-Curie Memorial Institute, Krakow Branch, Poland

${ }^{2}$ Center of Oncology, M. Sklodowska-Curie Memorial Institute, Krakow Branch, Kraków, Poland; Center of Oncology, Gynecologic Oncology Department, M. Sklodowska-Curie Memorial Institute, Krakow Branch, Poland

${ }^{3}$ Gynecology and Oncology Department of the Lukaszczyk Oncological Center in Bydgoszcz, Poland; Chair of Radiotherapy, Oncology and Gynecologic Oncology of the Ludwik Rydygier Medical College in Bydgoszcz, Mikolaj Kopernik University, Torun, Poland

${ }^{4}$ Microbiology and Oncological Immunology Department of Ludwik Rydygier Medical College in Bydgoszcz, Mikolaj Kopernik University, Poland

${ }^{5}$ Department of Pediatry Jagiellonian University Medical College

\title{
The possible use of the blood serum concentration measurements of SHLA-G in women with endometrial and cervical cancers during radiotherapy as an indicator of the status of the tumour microenvironment
}

Corresponding author:

Magdalena Dutsch-Wicherek Department of Pediatry Jagiellonian University Medical College, e-mail: mowicher@gmail.com
Medical Research Journal 2018; Volume 3, Number 4, 204-210 10.5603/MRJ.a2018.0033 Copyright (C) 2018 Via Medica ISSN 2451-2591

\begin{abstract}
Background: The selective suppression of cytotoxic immune cells constitutes a crucial event in the development of malignancy. This phenomenon increases in accordance with the growth of a tumor and is just one result of the increased expression in the cancer milieu of those proteins, such as human leukocyte antigen $G$ (HLA-G) and its soluble form (sHLA-G). Given that radiotherapy may influence immune system activity, we aimed to measure (sHLA-G) serum levels both before and after the radiotherapy due to endometrial or cervical cancer.

Methods: We assessed the SHLA-G blood serum concentration levels in a group of 43 patients (28 and 15 diagnosed with cervical cancer and endometrial cacer respectively), who received primary or adjuvant radiotherapy. We assessed the blood serum concentrations of the sHLA-G through a series of measurements taken before and four days after the latest radiation dosage using an ELISA kit.

Results: Median serum sHLA-G levels significantly decreased after radiotherapy $(5.63 \mathrm{U} / \mathrm{ml}$; range 0.00 - 344.55; vs $5.57 \mathrm{U} / \mathrm{ml} ; 0.00-94.02 ; P=0.045)$. The changes of sHLA-G levels didn't influence patients' survival. Pretreatment and post-treatment SHLA-G levels were negatively correlated with patients' age ( $R$ Spearman $=-0.45, P=0.041 ; R$ Spearman $=-0.46 . P=0.038$.

Conclusions: The detected levels of sHLA-G blood serum concentrations may supply clinically applicable information regarding the status of the tumor microenvironment - that is, the size and the degree of suppression of the tumor environment - where the tumor-immune cell interaction is realized. Finally, this information may also prove helpful in the treatment of cancer.
\end{abstract}

Key words: Ovarian cancer, endometrial cancer, sHLA-G

Med Res J 2018; 3 (4): 204-210

\section{Introduction}

The suppression of the immune system constitutes a crucial event in the development of malignancy. It is known that this phenomenon increases in accordance with the growth of a tumour as a result of the increased expression in the cancer milieu of the proteins responsible for the evasion of cancer cells from immune system surveillance. The suppressive environment is related not only to the membrane form of expression, but also to the secretion of the soluble form of these proteins, such as Fas-L [1], RCAS1 [2-3], and HLA-G [4], to the 
extracellular matrix of the cancer microenvironment. This profile of the microenvironment is also determined by the infiltration of immune regulatory cells (e.g., Treg) into the cancer microenvironment itself [5] and to the polarization of the tumour microenvironment by an increase in Th2 cytokine (e.g., IL-10) concentration [6]. Tylor et al. have demonstrated that the recruitment of Tregs to the cancer microenvironment inhibits an effective antitumor immune response [7]. It has been shown that radiotherapy affects the function of the immune system. Muroyama et al. have shown that RT-induced proliferation of Treg cells and the post-RT intratumoral Treg cells have a suppressive function [8]. Generally, the clinical studies suggest that radiotherapy increase the production of Tregs and their recruitment to local tumour microenvironment [9].

The presence of these factors in the tumour microenvironment may be discerned in the cancer milieu. Furthermore, the levels of its expression or the concentrations of its soluble forms can be determined not only in the tumour microenvironment but also in the peripheral blood. Since these factors are crucial for the development of the phenomenon, the possibility of assessing the levels in women treated for gynaecological malignancies would seem to constitute a clinically applicable indicator of the status of the tumour microenvironment - that is, the size and the degree of suppression of the tumour environment. Most likely, the use of the information deriving from the interactions between cancer and its stroma and the immune cells in the tumour microenvironment will spur improvement in the therapy for gynaecological malignancies. As of now, treatment for endometrial cancers remains a clinical problem [10].

We focused on our studies on the cancer microenvironment and on the proteins present there and deriving from the cancer milieu. Most likely such proteins like HLA-G can be used as biomarkers not specifically linked with the particular type of gynaecological malignancy, as they have also been found under normal physiological conditions in women's reproductive tracts (e.g., in the feto-maternal interface) [11]. The blood serum profiles of these biomarkers may supply interesting information for clinicians, such as the fact that developing cancer modifies its own microenvironment.

HLA-G is an antigen whose participation in the regulation of the immune system has been well documented [11]. HLA-G is one of the proteins involved in the regulation of the interaction of the tumour and immune cells that takes place in the microenvironment of a growing tumour [12, 13]. HLA-G is believed to protect the target cells that are deficient in HLA class I antigens from NK-dependent lysis by interacting on their surfaces with killer-inhibitory receptors. Tumour cells may, therefore, be excluded from the host immune response. Expression of the suppressive molecule
HLA-G differs from that found in other types of malignancies. In general, an increased expression of HLA-G is known to be associated with disease progression not only in ovarian [14], endometrial [15], and breast [16] cancers, but also in non-gynaecological types of malignancies, such as bladder cancers [17], and retinoblastoma [18]. Park et al. have demonstrated that cells can generate the soluble HLA-G (HLA-G1 and HLA-G5) by the dual mechanism of alternative splicing and proteolytic shedding and that the soluble form of HLA-G is able to inhibit the lytic activity of NK cells [11]. The concentration of the soluble form of sHLA-G in the peripheral blood could demonstrate the level of suppression by the tumour environment. Ben Yahia et al. have demonstrated the growth of SHLA-G in early stages (Stages I and II) as well as the correlation with grading of endometrial cancer. The alteration of the level of SHLA-G was associated with the rapid spread of the disease [19].

The presence in the peripheral blood proteins such as SHLA-G might be related to the suppressive influence of cancer cells on the immune system. This information detected in peripheral blood is valuable and applicable especially from a clinical point of view. For this reason, we decided in our study to evaluate the sHLA-G blood serum concentration levels both before and after the radiotherapy in patients treated for cervical and endometrial carcinomas.

\section{Material and methods}

\section{Human subject}

In the case of early-stage cervical cancer patients (up to and including IB1 according to FIGO classification) a radical hysterectomy and adnexectomy with pelvic and paraaortic lymphadenectomy were performed followed by brachytherapy and external beam radiation. More advanced stages were treated with primary radiotherapy with or without concurrent chemotherapy. Patients with endometrial cancer were treated surgically in all cases and simple, extrafascial hysterectomy with bilateral ovariectomy with pelvic lymphadenectomy was performed. All of the analyzed patients with endometrial cancer were treated with adjuvant external beam radiation and brachytherapy with or without chemotherapy. The mean age of the patients included was 58 (range 35-84 years). The patients had undergone treatment in the Gynecologic Oncology Department of the M. Sklodowska-Curie Memorial Institute or in the Gynecology and Oncology Department of the Lukaszczyk Oncological Center, respectively in Krakow and Bydgoszcz between January 2007 and September 2010. The patient's consent was obtained in each case. Prior to the study, the approval of the Jagiellonian Uni- 
versity Ethical Committee (KBET/135/B/2007) was also obtained. Information on all the patients who died was retrieved from the database of the Kujawsko-Pomorski and Malopolski regional office of the National Health System of Poland. We have analyzed longterm outcomes after radiotherapy regarding overall survival (OS).

\section{ELISA}

The blood was collected to a serum collection tube both directly prior to radiotherapy and on the fourth day following the last radiation dosage. A clot was allowed to form at room temperature for 30-60 minutes. The tube was placed on ice for 30 minutes in order to contract a clot. The serum samples were then centrifuged at $3000 \mathrm{xg}$ for 10 minutes at room temperature. The supernatants $1.0-2.0 \mathrm{ml}$ were collected and stored at $-80^{\circ} \mathrm{C}$. The analysis of sHLA-G concentration in the serum samples was performed in the Department of Analytical Biochemistry, Faculty of Biochemistry, Biophysics, and Biotechnology, Jagiellonian University. The soluble human leukocyte antigen-G (sHLA-G) was detected using the sHLA-G sandwich ELISA kit (BioVendor-Exibo, Czech Republic). Briefly stated, the blood plasma samples were diluted twice and incubated for 1 hour in the 96-well microplate precoated with the monoclonal anti-sHLA-G antibodies. Following incubation, the wells were washed and then filled with the monoclonal anti-human beta-2-microglobulin antibodies labeled with horseradish peroxidase. After an additional 1 hour of incubation, the wells were again washed, and the colour reaction was developed using tetramethyl benzidine (TMB) substrate. The absorbance values were measured at $450 \mathrm{~nm}$ on a microplate reader followed by the calculation of the sHLA-G concentrations. The assay was calibrated using a set of sHLA-G standards provided by the producer of the kit.

\section{Statistical analysis}

The distribution of variables in the study groups of women checked with the use of the Shapiro-Wilk test showed that each of the women was different from normal. Pre- and postoperative sHLA-G concentrations levels were analyzed using the Wilcoxon test. The statistical significance in the levels of sHLA-G, both pre- and post treatment, between cervical cancer and endometrial cancer patients groups was determined by the Mann-Whitney Test. The Mann-Whitney test was also used for the calculation of differences related to FIGO stage and cancer grade. For survival evaluation, Kaplan-Meier curves analysis was performed.

\section{Results}

The statistically significant differences in sHLA-G blood serum concentration level were identified before radiotherapy and on the fourth day following the collection of the last dosage of radiotherapy (Median $5.63 \mathrm{U} / \mathrm{ml}$; range 0.00 - 344.55; vs $5.57 \mathrm{U} / \mathrm{ml}$; $0.00-94.02 ; p=0.04$, respectively). The results are summarized in Table 2.

No statistically significant differences were identified in the sHLA-G blood serum concentration levels with respect to the clinicopathological parameters, such as FIGO stage and tumour grade. Similarly, there were no differences in pre- and post-treatment SHLA-G levels between cervical and endometrial cancer patients. Pretreatment sHLA-G levels in the sera of patients with I and II stage disease was not significantly different from patients with stage III and IV disease $(5.63 \mathrm{U} / \mathrm{ml}$, range $0-71.82$, vs. $5.45 \mathrm{U} / \mathrm{ml}$, range $0-344.55 \mathrm{U} / \mathrm{ml}$, $P=0.735)$. Similarly, the difference in post-treatment levels of SHLA-G was not statistically significant $(5.75 \mathrm{U} / \mathrm{ml}, 0-41.28$ vs $5.09 \mathrm{U} / \mathrm{ml}, 0-94.02, \mathrm{P}=0.474)$. The difference in sHLA median levels between well and moderately differentiated tumors was not different from poorly differentiated tumors, both in pre- and post-treatment evaluation $(5.63 \mathrm{U} / \mathrm{ml}, 0-71.82$ vs. $5.45 \mathrm{U} / \mathrm{ml}$, $0-344.55 ; \mathrm{P}=0.71$ and $5.75 \mathrm{U} / \mathrm{ml}, 0-41.28$ vs. $5.09 \mathrm{U} / \mathrm{ml}$, 0-94.02 U/ml, $\mathrm{P}=0.622$ ).

We have found significant, negative correlation between patients' age both pre- and postreatment and sHLA-G levels ( $R$ Spearman $=-0.45, P=0.041 ; R$ Spearman $=-0.46 . P=0.038$ respectively).

No statistically significant differences were identified in the SHLA-G blood serum concentration levels before and after radiotherapy with respect to a long-term outcome. When patients were divided into two groups: patients with decreased or stable post-treatment SHLA-G levels (Group 1, $n=31$ ) and patients with increased post-treatment sHLA-G levels (Group 2, $n=12$ ), there were no statistical significant difference in patients' survival (1592 vs. 657 days, $P=0.60$; Figure 1 ).

\section{Discussion}

We have found statistically significant differences between the levels of the blood serum concentrations of SHLA-G as measured before and after radiotherapy in patients treated for cervical and endometrial carcinomas. Radiotherapy induces single- and double-stranded DNA breaks leading to apoptosis [20], but it has been shown that RT affects the immune system activity, including the induction of a systemic antitumor response, with a pro-inflammatory activity and an abscopal effect [21, 22]. RT has also been demonstrated 
Table 1. Clinicopathological characteristics and treatment modalities of the patients

\begin{tabular}{|c|c|c|c|c|c|c|c|}
\hline $\begin{array}{l}\text { In this study, we } \\
\text { analyzed the blood } \\
\text { serum samples } \\
\text { obtained from } 43 \\
\text { patients, including } \\
\text { No }\end{array}$ & Age & Cancer & FIGO & Histopathology & Grade & Surgery & $\begin{array}{l}\text { Chemo- } \\
\text { therapy }\end{array}$ \\
\hline 1 & 50 & Cervical cancer & IB1 & squamous cell carcinoma & 3 & Yes & No \\
\hline 2 & 46 & Cervical cancer & IB1 & squamous cell carcinoma & 3 & Yes & Yes \\
\hline 3 & 35 & Cervical cancer & IB2 & squamous cell carcinoma & 2 & No & No \\
\hline 4 & 50 & Cervical cancer & $\| A$ & squamous cell carcinoma & 2 & No & Yes \\
\hline 5 & 51 & Cervical cancer & $\| A$ & squamous cell carcinoma & 3 & No & Yes \\
\hline 6 & 48 & Cervical cancer & IIB & squamous cell carcinoma & 2 & No & No \\
\hline 7 & 65 & Cervical cancer & IIB & adenocarcinoma & 2 & No & Yes \\
\hline 8 & 65 & Cervical cancer & IIB & squamous cell carcinoma & 2 & No & Yes \\
\hline 9 & 52 & Cervical cancer & IIB & squamous cell carcinoma & 2 & No & Yes \\
\hline 10 & 52 & Cervical cancer & IIB & adenocarcinoma & 1 & No & Yes \\
\hline 11 & 62 & Cervical cancer & IIB & squamous cell carcinoma & 3 & No & Yes \\
\hline 12 & 42 & Cervical cancer & IIB & squamous cell carcinoma & 3 & No & Yes \\
\hline 13 & 48 & Cervical cancer & IIIB & squamous cell carcinoma & 2 & No & No \\
\hline 14 & 63 & Cervical cancer & IIIB & squamous cell carcinoma & 1 & No & No \\
\hline 15 & 58 & Cervical cancer & IIIB & squamous cell carcinoma & 3 & No & Yes \\
\hline 16 & 72 & Cervical cancer & IIIB & squamous cell carcinoma & 3 & No & Yes \\
\hline 17 & 48 & Cervical cancer & IIIB & squamous cell carcinoma & 2 & No & No \\
\hline 18 & 52 & Cervical cancer & IIIB & squamous cell carcinoma & 2 & No & Yes \\
\hline 19 & 49 & Cervical cancer & IIIB & adenocarcinoma & 2 & No & Yes \\
\hline 20 & 47 & Cervical cancer & IVB & squamous cell carcinoma & 2 & No & Yes \\
\hline 21 & 58 & Cervical cancer & IIIB & squamous cell carcinoma & 3 & No & Yes \\
\hline 22 & 43 & Cervical cancer & IIIB & squamous cell carcinoma & 2 & No & Yes \\
\hline 23 & 52 & Cervical cancer & IIB & squamous cell carcinoma & 2 & No & Yes \\
\hline 24 & 68 & Cervical cancer & $\| A$ & squamous cell carcinoma & 2 & No & Yes \\
\hline 25 & 62 & Cervical cancer & IIB & squamous cell carcinoma & 3 & No & Yes \\
\hline 26 & 46 & Cervical cancer & IB1 & squamous cell carcinoma & 3 & Yes & Yes \\
\hline 27 & 68 & Cervical cancer & $\| A$ & squamous cell carcinoma & 2 & No & Yes \\
\hline 28 & 48 & Cervical cancer & IIIB & squamous cell carcinoma & 2 & No & No \\
\hline 29 & 66 & Endometrial cancer & IB & $\begin{array}{c}\text { endometrioid } \\
\text { adenocarcinoma }\end{array}$ & 3 & Yes & Yes \\
\hline 30 & 79 & Endometrial cancer & IB & $\begin{array}{l}\text { endometrioid } \\
\text { adenocarcinoma }\end{array}$ & 2 & Yes & No \\
\hline 31 & 74 & Endometrial cancer & IB & $\begin{array}{l}\text { endometrioid } \\
\text { adenocarcinoma }\end{array}$ & 3 & Yes & Yes \\
\hline 32 & 52 & Endometrial cancer & IB & $\begin{array}{c}\text { endometrioid } \\
\text { adenocarcinoma }\end{array}$ & 2 & Yes & No \\
\hline 33 & 61 & Endometrial cancer & IIIA & $\begin{array}{c}\text { endometrioid } \\
\text { adenocarcinoma }\end{array}$ & 2 & Yes & Yes \\
\hline 34 & 66 & Endometrial cancer & IIIB & $\begin{array}{c}\text { endometrioid } \\
\text { adenocarcinoma }\end{array}$ & 1 & Yes & No \\
\hline
\end{tabular}


Table $1 \mathrm{~cd}$. Clinicopathological characteristics and treatment modalities of the patients

\begin{tabular}{|c|c|c|c|c|c|c|c|}
\hline $\begin{array}{l}\text { In this study, we } \\
\text { analyzed the blood } \\
\text { serum samples } \\
\text { obtained from } 43 \\
\text { patients, including } \\
\text { No }\end{array}$ & Age & Cancer & FIGO & Histopathology & Grade & Surgery & $\begin{array}{l}\text { Chemo- } \\
\text { therapy }\end{array}$ \\
\hline 35 & 74 & Endometrial cancer & IIIC1 & $\begin{array}{l}\text { endometrioid } \\
\text { adenocarcinoma }\end{array}$ & 3 & Yes & Yes \\
\hline 36 & 61 & Endometrial cancer & IIIB & $\begin{array}{c}\text { endometrioid } \\
\text { adenocarcinoma }\end{array}$ & 2 & Yes & No \\
\hline 37 & 52 & Endometrial cancer & II & $\begin{array}{c}\text { endometrioid } \\
\text { adenocarcinoma }\end{array}$ & 1 & Yes & No \\
\hline 38 & 46 & Endometrial cancer & IIIA & serous adenocarcinoma & 3 & Yes & Yes \\
\hline 39 & 78 & Endometrial cancer & IIIA & serous adenocarcinoma & 3 & Yes & Yes \\
\hline 40 & 84 & Endometrial cancer & $\|$ & undifferentiated carcinoma & 3 & Yes & No \\
\hline 41 & 70 & Endometrial cancer & $\|$ & $\begin{array}{c}\text { endometrioid } \\
\text { adenocarcinoma }\end{array}$ & 1 & Yes & No \\
\hline 42 & 74 & Endometrial cancer & IIIC1 & $\begin{array}{c}\text { endometrioid } \\
\text { adenocarcinoma }\end{array}$ & 3 & Yes & Yes \\
\hline 43 & 70 & Endometrial cancer & ॥ & $\begin{array}{l}\text { endometrioid } \\
\text { adenocarcinoma }\end{array}$ & 1 & Yes & No \\
\hline
\end{tabular}

Table 2. The difference in pre- and post-treatment serum sHLA-G levels

\begin{tabular}{llll}
\hline & Median & Range & P-value \\
Pretreatment & $5.63 \mathrm{U} / \mathrm{ml}$ & $0.00-344.55$ & $\mathrm{P}=0.04$ \\
Post-treatment & $5.57 \mathrm{U} / \mathrm{ml}$ & $0.00-94.02$ & \\
\hline
\end{tabular}

to exert an immunosuppressive effect, increased levels of functionally active Treg lymphocytes were detected following radiotherapy [23]. lonizing radiation has also been demonstrated to modulate the HLA-G expression. Michelin et al. have demonstrated that irradiation downregulated cell surface and total HLA-G levels and increased SHLA-G1 in the medium of the melanoma cell line. Authors concluded that radiotherapy might induce a proteolytic cleavage of this molecule [24]. Most probably decreasing serum level of SHLA-G observed after radiotherapy is linked with reduction of the tumour mass that the patients underwent during surgery before adjuvant radiotherapy.

The suppression of the immune system constitutes a crucial event in the development of malignancy, particularly in cases of cancer relapse. Surgery, chemoand radiotherapy all have different effects on tumour and immune cell interaction $[25,26]$. Since, on the one hand, the immune system can demonstrate anti-tumour activity, but, on the other hand, can promote tumour growth, the degree of the suppressive influence of cancer cells on the immune system may be able to determine the success of the treatment for a cancer relapse [2]. Nevertheless, it is not common practice to evaluate the suppressive influence of cancer cells on the immune system. This detection could be helpful in monitoring treatment processes and might reflect the influence of this treatment on the restoration of proper immune system activity. sHLA-G, however, has been observed in blood sera of patients with gynaecological malignancies [15]. Furthermore, sHLA-G has not yet been studied in relation to the applied surgery in cases of gynaecological malignancies.

HLA-G expression has been observed in endometrial cancer and can be compared with the expression reported in various other malignances. In immunohistochemical staining, HLA-G expression varied between $40 \%$ and $55 \%$ according to different studies [15, 27]. This discrepancy could be the result of the different characteristics of the patients included in the study, such as being in an advanced stage of the disease or having a tumor with non-endometrioid histology. Barrier et al. found a correlation between HLA-G expression and increasing FIGO stage which could serve as a pre-operative indicator of dissemination [15]. Contrary to our study we did not observe a correlation between the FIGO stage and the blood serum concentration levels of SHLA-G. Most likely this has to do with the character- 


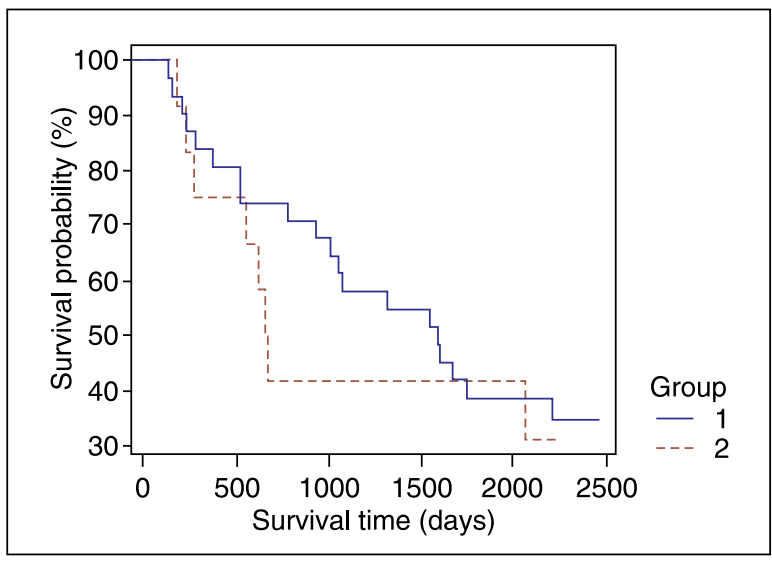

Figure 1. Kaplan-Meier survival curves for analyzed patients. Group 1: patients with decreased or stable posttreatment sHLA-G levels; Group 2: patients with increased post-treatment sHLA-G levels (1592 vs 657 days, $P=0.60$ )

istics of the patients included in the study, where most patients have advanced diseases [11].

HLA-G expression was associated with disease progression in patients with cervical cancer. In the study of Li et al., the expression of HLA-G molecule gradually increased from preinvasive stages to advanced cancers, indicating the role of HLA-G in tumour progression [28]. Additionally, Dong et al., indicates, that the HLA-G expression is related to HPV16/18 infection [29]. However, tissue expression of HLA-G may not directly reflect serum levels of soluble HLA-G. Similarly to our study, in the paper by Samulels et al., patients survival was not influenced by serum sHLA-G levels. Additionally, the authors also did not find any association between SHLA-G levels and clinicopathological characteristic of cervical cancer [30].

This serial method of measurement may help to reveal the relationship between the applied therapy and the size and degree of the suppression of the tumour environment. Furthermore, such results could indicate that a change in therapy is needed; it could also provide a strong, clinical indication and foundation for the earlier application of molecular therapies, such as immunotherapy.

\section{Conclusions}

The detected SHLA-G blood serum concentrations may supply clinically applicable information regarding the status of the tumour microenvironment - that is, the size and the degree of suppression of the tumour environment - where the tumour-immune cell interaction is realized. Finally, this information may also prove helpful in the treatment of cancer.

\section{Acknowledgements}

We wish to thank Professor Pawel Mak for their help. This work was funded by the Polish Ministry of Science, Grant Number 0888/B/P01/2008/35 in 2008/2009.

\section{Statement of competing interests}

The authors declare no competing financial interest and no conflicts of interests.

\section{List of abbreviations}

HLA-G - uman leukocyte antigen $G$

sHLA-G - Soluble Human Leukocyte Antigen-G

RCAS1 - receptor-binding cancer antigen expressed on SiSo cells

Treg - Regulatory T cells

$\mathrm{RT}$ - radiotherapy

\section{References}

1. Fournel S, Aguerre-Girr M, Huc X, et al. Cutting edge: soluble HLA-G1 triggers CD95/CD95 ligand-mediated apoptosis in activated CD8+ cells by interacting with CD8. J Immunol. 2000; 164(12): 6100-6104 indexed in Pubmed: 10843658.

2. Dutsch-Wicherek M, Wicherek $L$. The association of RCAS1 serum concentration with the reversibility or irreversibility of the process of immune cytotoxic activity restriction during normal menstrual cycle, cancer relapse, and surgical treatment for various types of squamous cell carcinomas and adenocarcinomas. Am J Reprod Immunol. 2008; 59(3): 266-275, doi: 10.1111/j.1600-0897.2007.00575.x, indexed in Pubmed: 18275520

3. Wicherek L. Alterations in RCAS1 serum concentration levels during the normal menstrual cycle and the lack of analogical changes in ovarian endometriosis. Am J Reprod Immunol 2008: 59(6): 535-544 doi: 10.1111/j.1600-0897.2008.00584.x, indexed in Pubmed: 18422812.

4. Rebmann V, Regel J, Stolke D, et al. Secretion of sHLA-G molecules in malignancies. Semin Cancer Biol. 2003; 13(5): 371-377, indexed in Pubmed: 14708717

5. Wilczynski JR, Kalinka J, Radwan M. The role of T-regulatory cells in pregnancy and cancer. Front Biosci. 2008; 13: 2275-2289, indexed in Pubmed: 17981709.

6. Sheu BC, Lin $\mathrm{RH}$, Lien $\mathrm{HC}$, et al. Predominant Th2/Tc2 polarity of tumor-infiltrating lymphocytes in human cervical cancer. J Immunol. 2001; 167(5): 2972-2978, indexed in Pubmed: 11509647

7. Taylor NA, Vick SC, Iglesia MD, et al. Treg depletion potentiates checkpoint inhibition in claudin-low breast cancer. J Clin Invest. 2017: 127(9): 3472-3483, doi: 10.1172/JCl90499, indexed in Pubmed: 28825599

8. Muroyama Y, Nirschl TR, Kochel CM, et al. Stereotactic Radiotherapy Increases Functionally Suppressive Regulatory T Cells in the Tumor Microenvironment. Cancer Immunol Res. 2017; 5(11): 992-1004, doi: 10.1158/2326-6066.CIR-17-0040, indexed in Pubmed: 28970196.

9. American Cancer Society. Cancer Facts and Figures 2008. Atlanta:American Cancer Society. ; 2008

10. Liu S, Sun X, Luo J, et al. Effects of radiation on T regulatory cells in normal states and cancer: mechanisms and clinical implications. Am J Cancer Res. 2015; 5(11): 3276-3285, indexed in Pubmed: 26807310.

11. Park GM, Lee S, Park B, et al. Soluble HLA-G generated by proteolytic shedding inhibits NK-mediated cell lysis. Biochem Biophys Res Commun. 2004; 313(3): 606-611, indexed in Pubmed: 14697234.

12. Rebmann V, Regel J, Stolke D, et al. Secretion of sHLA-G molecules in malignancies. Semin Cancer Biol. 2003; 13(5): 371-377, indexed in Pubmed: 14708717 
13. Pistoia V, Morandi F, Wang X, et al. Soluble HLA-G: Are they clinically relevant? Semin Cancer Biol. 2007; 17(6): 469-479, doi: 10.1016/i. semcancer.2007.07.004, indexed in Pubmed: 17825579.

14. Sheu JJC, Shih IM. Clinical and biological significance of HLA-G expression in ovarian cancer. Semin Cancer Biol. 2007; 17(6): 436-443 doi: 10.1016/j.semcancer.2007.06.012, indexed in Pubmed: 17681474

15. Barrier BF, Kendall BS, Sharpe-Timms KL, et al. Characterization of human leukocyte antigen-G (HLA-G) expression in endometrial adenocarcinoma. Gynecol Oncol. 2006; 103(1): 25-30, doi: 10.1016/ ygyno.2006.01.045, indexed in Pubmed: 16530254

16. Lefebvre S, Antoine M, Uzan S, et al. Specific activation of the non-classical class I histocompatibility HLA-G antigen and expression of the ILT2 inhibitory receptor in human breast cancer. J Pathol. 2002; 196(3) 266-274, doi: 10.1002/path.1039, indexed in Pubmed: 11857488

17. El-Chennawi FA, Auf FA, El-Diasty AM, et al. Expression of HLA-G in cancer bladder. Egypt J Immunol. 2005; 12(1): 57-64, indexed in Pubmed: 16734140.

18. Adithi M, Kandalam M, Ramkumar HL, et al. Retinoblastoma: expression of HLA-G. Ocul Immunol Inflamm. 2006; 14(4): 207-213, doi: 10.1080/09273940600826497, indexed in Pubmed: 16911982.

19. Ben Yahia H, Babay W, Bortolotti D, et al. Increased plasmatic soluble HLA-G levels in endometrial cancer. Mol Immunol. 2018; 99: 82-86 doi: 10.1016/j.molimm.2018.04.007, indexed in Pubmed: 29730546.

20. Liauw SL, Connell PP, Weichselbaum RR. New paradigms and future challenges in radiation oncology: an update of biological targets and technology. Sci Transl Med. 2013; 5(173): 173sr2, doi: 10.1126/scitransImed.3005148, indexed in Pubmed: 23427246.

21. Postow MA, Callahan MK, Barker CA, et al. Immunologic correlates of the abscopal effect in a patient with melanoma. N Engl J Med. 2012; 366(10): 925-931, doi: 10.1056/NEJMoa1112824, indexed in Pubmed: 22397654.

22. Schreiber RD, Old LJ, Smyth MJ. Cancer immunoediting: integrating immunity's roles in cancer suppression and promotion. Science. 2011;
331(6024): 1565-1570, doi: 10.1126/science.1203486, indexed in Pubmed: 21436444

23. Muroyama Y, Nirschl TR, Kochel CM, et al. Stereotactic Radiotherapy Increases Functionally Suppressive Regulatory T Cells in the Tumor Microenvironment. Cancer Immunol Res. 2017: 5(11): 992-1004, doi: 10.1158/2326-6066.CIR-17-0040, indexed in Pubmed: 28970196.

24. Michelin S, Gallegos CE, Dubner D, et al. Ionizing radiation modulates the surface expression of human leukocyte antigen-G in a human melanoma cell line. Hum Immunol. 2009; 70(12): 1010-1015, doi: 10.1016/j. humimm.2009.07.030, indexed in Pubmed: 19665041.

25. Chen R, Alvero AB, Silasi DA, et al. Inflammation, cancer and chemoresistance: taking advantage of the toll-like receptor signaling pathway. Am J Reprod Immunol. 2007; 57(2): 93-107, doi: 10.1111/j.1600-0897.2006.00441.x, indexed in Pubmed: 17217363.

26. Bijen CBM, Bantema-Joppe EJ, de Jong RA, et al. The prognostic role of classical and nonclassical MHC class I expression in endometrial cancer. Int J Cancer. 2010; 126(6): 1417-1427, doi: 10.1002/ijc.24852, indexed in Pubmed: 19728333

27. Emens LA. Chemotherapy and tumor immunity: an unexpected collaboration. Front Biosci. 2008; 13: 249-257, indexed in Pubmed: 17981543.

28. Li XJ, Zhang $X$, Lin A, et al. Human leukocyte antigen-G (HLA-G) expression in cervical cancer lesions is associated with disease progression. Hum Immunol. 2012; 73(9): 946-949, doi: 10.1016/j. humimm.2012.07.041, indexed in Pubmed: 22820627.

29. Dong Dd, Yang H, Li Ke, et al. Human leukocyte antigen-G (HLA-G) expression in cervical lesions: association with cancer progression, HPV 16/18 infection, and host immune response. Reprod Sci. 2010; 17(8): 718723, doi: 10.1177/1933719110369183, indexed in Pubmed: 20445010.

30. Samuels S, Ferns DM, Meijer D, et al. High levels of soluble MICA are significantly related to increased disease-free and disease-specific survival in patients with cervical adenocarcinoma. Tissue Antigens. 2015; 85(6): 476-483, doi: 10.1111/tan.12562, indexed in Pubmed: 25871737 